\title{
Health-related quality of life in hospitalized older patients with versus without prolonged use of opioid analgesics, benzodiazepines, and z-hypnotics: a cross- sectional study
}

\author{
Socheat Cheng ${ }^{1,2^{*}}$ (D), Tahreem Ghazal Siddiqui ${ }^{1,2}$, Michael Gossop ${ }^{3}$, Knut Stavem ${ }^{1,2,4}$,
}

Espen Saxhaug Kristoffersen ${ }^{5,6}$ and Christofer Lundqvist ${ }^{1,2,6}$

\begin{abstract}
Background: Central nervous system depressant medications (CNSDs) such as opioid analgesics and sedativehypnotics are commonly prescribed to older patients for the treatment of chronic pain, anxiety and insomnia. Yet, while many studies reported potential harms, it remains unknown whether persistent use of these medications is beneficial for older patients' self-reported health-related quality of life (HRQOL). The present study clarified this knowledge gap through comparing HRQoL of hospitalized older patients with versus without using CNSD drugs for $\geq 4$ weeks. Moreover, we explored the relationship between such use and HRQoL, adjusting for the effects of polypharmacy, comorbidity burden and other clinically relevant covariates.

Methods: The study was cross-sectional and included 246 older patients recruited consecutively from somatic departments of a large regional university hospital in Norway. We defined prolonged CNSD use as using opioids, benzodiazepines and/or z-hypnotics for $\geq 4$ weeks. Patients' self-reported HRQoL were measured with scales of the EuroQol EQ-5D-3L instrument. Data analyses were mainly descriptive statistics and regression models.

Results: Patients with prolonged use of CNSDs reported lower scores on both EQ-5D index and EQ VAS compared with those without such use $(p<0.001)$. They had higher odds of having more problems performing usual activities $(\mathrm{OR}=3.37,95 \% \mathrm{Cl}: 1.40$ to 8.13$)$, pain/discomfort $(\mathrm{OR}=2.06,95 \% \mathrm{Cl}: 1.05$ to 4.04$)$, and anxiety/depression ( $\mathrm{OR}=3.77$, 95\% Cl: 1.82 to 7.82$)$.

In multivariable regression models, there was no significant association between prolonged CNSD use and HRQoL when including pain as a predictor variable. In models not including pain, CNSD use was strongly associated with HRQoL (adjusted for sociodemographic background, polypharmacy, comorbidity, anxiety and depressive symptoms, (Continued on next page)
\end{abstract}

\footnotetext{
* Correspondence: socheat.cheng@ahus.no

${ }^{1}$ Health Services Research Unit (HøKH), Akershus University Hospital, PO Box 1000, 1478 Lørenskog, Norway

${ }^{2}$ Institute of Clinical Medicine, Campus Ahus, Faculty of Medicine, University of Oslo, Lørenskog, Norway

Full list of author information is available at the end of the article
}

(c) The Author(s). 2020 Open Access This article is licensed under a Creative Commons Attribution 4.0 International License, which permits use, sharing, adaptation, distribution and reproduction in any medium or format, as long as you give appropriate credit to the original author(s) and the source, provide a link to the Creative Commons licence, and indicate if changes were made. The images or other third party material in this article are included in the article's Creative Commons licence, unless indicated otherwise in a credit line to the material. If material is not included in the article's Creative Commons licence and your intended use is not permitted by statutory regulation or exceeds the permitted use, you will need to obtain permission directly from the copyright holder. To view a copy of this licence, visit http://creativecommons.org/licenses/by/4.0/. The Creative Commons Public Domain Dedication waiver (http://creativecommons.org/publicdomain/zero/1.0/) applies to the data made available in this article, unless otherwise stated in a credit line to the data. 
(Continued from previous page)
regression coefficient $-0.19(95 \% \mathrm{Cl},-0.31$ to -0.06$)$.

Conclusions: Older patients with prolonged CNSD use reported poorer HRQoL. They also had more pain and higher depression scores. Prolonged use of CNSDs was not independently associated with higher HRQoL.

Keywords: Medication safety, Prescription drug abuse, Geriatric patients, Opioids, Z-drugs, Benzodiazepines, Patientcentered care, Old age

\section{Background}

Health-related quality of life (HRQoL) is a subjective and multidimensional construct, which can be conceptualized through reflecting on a patient's views, experiences or expectation of his or her own physical, mental, social and functional health [1]. Older people may have reduced HRQoL due to age-related progressive decline in physiological reserve and functional capacity [2]. Apart from multi-morbidity, cognitive deficits and psychological distress, inappropriate medication use and poor prescription quality may also undermine HRQoL, through causing drug-induced injuries [3-5].

Chronic pain, anxiety and insomnia are common in old age [6]. Pharmacological therapy of these conditions may involve the use of central nervous system depressant medications (CNSDs) such as opioid analgesics, benzodiazepines and z-hypnotics [7]. Although these medications are frequently prescribed, long-term effectiveness among older people was not shown $[8,9]$. Moreover, many studies underline misuse potentials and hazardous consequences of these medications among older patients [10]. Long-term opioid use, for instance, was found to be associated with major adverse effects such as dependence, opioid-induced hyperalgesia, sleepdisordered breathing, hormone dysfunction and immunosuppression [11]. Overuse of benzodiazepines and z-hypnotics likewise was found to be associated with reduced cognitive function, road-traffic accidents, respiratory depression, fractures, falls, and suicide [12, 13].

Research on long-term use of CNSD use in geriatric patients has mostly been restricted to condition-specific outcomes rather than patients' quality of life as a whole. Also, studies rarely adjust for the effects of multimorbidity and polypharmacy [14]. Thus, we compared self-reported HRQoL of hospitalized older patients with and without prolonged use of commonly prescribed CNSDs: opioids, benzodiazepines and z-hypnotics.

\section{Methods}

\section{Study design and setting}

This was a cross-sectional, in-hospital study, which recruited patients consecutively between May 2017 and September 2018, from three somatic departments of the Akershus University Hospital: Geriatrics, Internal Medicine and Neurology. The catchment area of the hospital covers approximately $10 \%$ of the total population of Norway. Due to an all-covering national health insurance, patients are admitted to the hospital regardless of their socioeconomic background.

\section{Inclusion and exclusion criteria}

Participants were recruited during the first few days of admission based on predefined inclusion and exclusion criteria. The study included hospitalized patients, aged between 65 and 90 years old. The exclusion criteria were Mini-Mental State Examination (MMSE) score $\leq 21$ (interpreted as incapacity to give informed consent) [15], pre-existing diagnosis of severe depression, stroke, dementia, psychotic disorders; serious visual or hearing impairment; and insufficient knowledge of Norwegian language, which could bias patients' responses to selfrated health questions. We precluded participants who were critically ill or in palliative treatment, defined by physicians in the study setting.

\section{Data collection}

After giving informed consent, all eligible participants responded to questionnaires containing questions on sociodemographic background, pain intensity, anxiety, depression and HRQoL. At this stage, the investigators were masked to information on CNSD use as this was registered in the electronic medical record (EMR), which could only be accessed once a written informed consent had been obtained. Having fulfilled this requirement, the EMRs were reviewed to document the use of CNSDs (types, duration, and use patterns) and comorbidity burden.

\section{Variables and data sources \\ Use of central nervous system depressants (CNSDs)}

We defined prolonged use of CNSDs as using opioid analgesics, benzodiazepines and/or z-hypnotics for $\geq 4$ weeks continuously up to the recruitment time point, while non-prolonged use was no use or use of these medications for $<4$ weeks. Data on this variable were collected through reviewing EMRs. To ensure data accuracy, we cross-checked for consistency of information in the EMR by checking with the patients and GP referral documents. 


\section{Assessment of health-related quality of life}

The EuroQol Group's EQ-5D-3L instrument was used to collect data on the HRQoL of study participants [16]. This instrument is a self-reported, standardized questionnaire, which is short, widely used and available in more than 170 languages, including Norwegian. It consists of two parts: the EQ-5D descriptive system and the EQ visual analogue scale (EQ VAS). The descriptive system contains five dimensions: mobility, self-care, usual activities, pain/discomfort and anxiety/depression. Each dimension has three levels of severity. Thus, a total of 243 possible health states can be assigned. Individual patients' health states are converted into an index value (EQ-5D index) which represents how good or bad a patient's overall HRQoL is, based on the valuation of health states by the general population. An EQ-5D index of 1 is anchored as full health, while 0 represents death. The calculation of EQ-5D index score was performed using the value set for England because values for Norway were not available. The EQ VAS is a $20 \mathrm{~cm}$ vertical visual analogue scale (VAS), on which participants record self-perceived health on a 0 to 100 scale, where 0 is "the worst health possible" and 100 "the best imaginable health". When filling in the EQ-5D questionnaire, participants were asked to refer to their current health status and situation [16].

\section{Sociodemographic and clinical variables}

Sociodemographic variables included sex, age (years), education (basic, secondary and higher education) and living alone (yes, no). Clinical variables entailed current pain intensity (measured on a $10 \mathrm{~cm}$ horizontal VAS) [17], anxiety and depressive symptoms (assessed with the Hospital Anxiety and Depression Scale - HADS) [18], comorbidity burden (defined as the total score of the Cumulative Illness Rating Scale for Geriatrics CIRS-G) [19], polypharmacy (using $\geq 5$ medications/day) [20]. The HADS is a 14-item questionnaire, containing two subscales: anxiety (7 questions) and depression (7 questions). Optimal cut-off values for diagnosing anxiety and depression in hospitalized older patients using HADS remain to be established [21, 22]. Therefore, we used anxiety and depression scores as continuous variables on 0 to 21 scales, with higher scores indicating more symptoms. The CIRS-G is a validated scale for assessing comorbidity and the burden of chronic illnesses in geriatric patients. It has 14 organ-system categories, scored from 0 to 4 , with higher scores indicating increased severity of medical conditions [23]. Data on sociodemographic status, pain intensity, anxiety and depression scores were all collected through a selfcompleted questionnaire, while data for comorbidity burden were collected through reviewing EMRs.

\section{Statistical analysis}

We compared participants' characteristics and HRQoL (EQ-5D dimension scores, EQ VAS and EQ-5D index score) using the chi-square test, student's t-test, or MannWhitney $\mathrm{U}$ test, as appropriate. We also performed a post-hoc analysis to assess differences in EQ VAS and EQ-5D index scores between patients who used only 1 type versus $\geq 2$ different types of CNSDs as well as among the users of the three listed medication groups.

Initially, we attempted to use ordered logistic regression analyses to assess the association between prolonged use of CNSDs and the five dimensions of the EQ-5D-3L, as they have three levels of severity. The proportional odds assumption was checked using the Brant test and was met for the models with mobility, self-care, pain/discomfort and anxiety/depression as the dependent variables. The model with usual activities as the dependent variable did not satisfy the assumption (Brant tests: $P<0.05$ ) [24] and was therefore analyzed with binary logistic regression analysis. For this model, we dichotomized responses into absence (level 1) or presence (level 2 and 3) of problems regarding usual activities. In the assessment of the relationship between prolonged CNSD use and problems regarding mobility, self-care and usual activities, we included the following covariates: sociodemographic background, polypharmacy and comorbidity burden, pain intensity (VAS) and anxiety and depression scores (HADS). To avoid over-adjustment, we dropped the variable pain intensity (VAS) from the model where pain/discomfort (EQ-5D) was the dependent variable as they both measure the same construct. For the same reason, we dropped anxiety and depression scores (HADS) as independent variables when anxiety/depression (EQ-5D) was the dependent variable. The results of ordered logistic regression analysis is interpreted as the odds of being in groups greater than $j$ versus those who are in groups less than or equal to $j$, where $j$ is the level of the dependent variable. This is constant across all levels of the dependent variable [24]. For example, the proportional odds ratio for the mobility dimension of the EQ-5D-3L represents the odds of being confined to bed (level 3) versus no/some problems in walking about (level 1 and 2), and also the odds of having some problems in walking about/being confined to bed (level 2 and 3) versus no problems in walking about (level 1).

We explored the association between prolonged use of CNSDs and overall HRQoL as assessed by the EQ-5D index in three different models, using hierarchical multiple linear regression analysis. The purpose was to gain a better understanding of the relationship. For Model 1, we adjusted for the effects of covariates: age, sex, education, living alone, polypharmacy and comorbidity burden. In Model 2, we added two extra independent variables to the model: anxiety and depression (HADS) scores, known to affect HRQoL [25]. Further, we created 
Model 3 by adding the variable pain intensity (VAS) to the Model 2, as we considered pain to be a possible confounder. As the percentage of missing values for EQ-5D$3 \mathrm{~L}$ was minimal $(n=7)$, complete case analysis was used. Multicollinearity was checked based on the variance inflation factor values and was not detected. Residual diagnostics was performed, and bootstrap confidence intervals were also calculated to confirm the main results. The results are presented with regression coefficient (unstandardized beta coefficients) with 95\% confidence interval (CI). Stata SE software, version 15 (StataCorp, College Station, TX, USA) was used for all statistical analyses. We chose a $5 \%$ significance level, using two-tailed tests.

\section{Patient and public involvement}

The present study engaged patient representatives, health professionals, and data protection officers in the design, performance, and dissemination of research results. We had regular meetings at the Akershus
University Hospital to discuss, update, and provide inputs on practical issues pertaining to the study.

\section{Results}

A total of 665 hospitalized patients aged 65-90 were consecutively approached during the study period. Of these, 227 patients declined to participate, 92 were precluded because of being in a critical medical condition or palliative treatment, and 100 were excluded based on predefined exclusion criteria. Hence, 246 older patients were eligible for the study. A total of 100 participants were prolonged users of CNSDs (Fig. 1); 70\% used only one type of CNSDs: zhypnotics $42 \%$, opioid analgesics $21 \%$, and benzodiazepines $7 \%$. The remaining $30 \%$ concurrently used $\geq 2$ different types of CNSDs. Participants with prolonged use of CNSDs comprised a higher proportion of females, were older, had less education, more polypharmacy, more comorbidity and higher pain intensity and depression scores than those without prolonged use (Table 1).

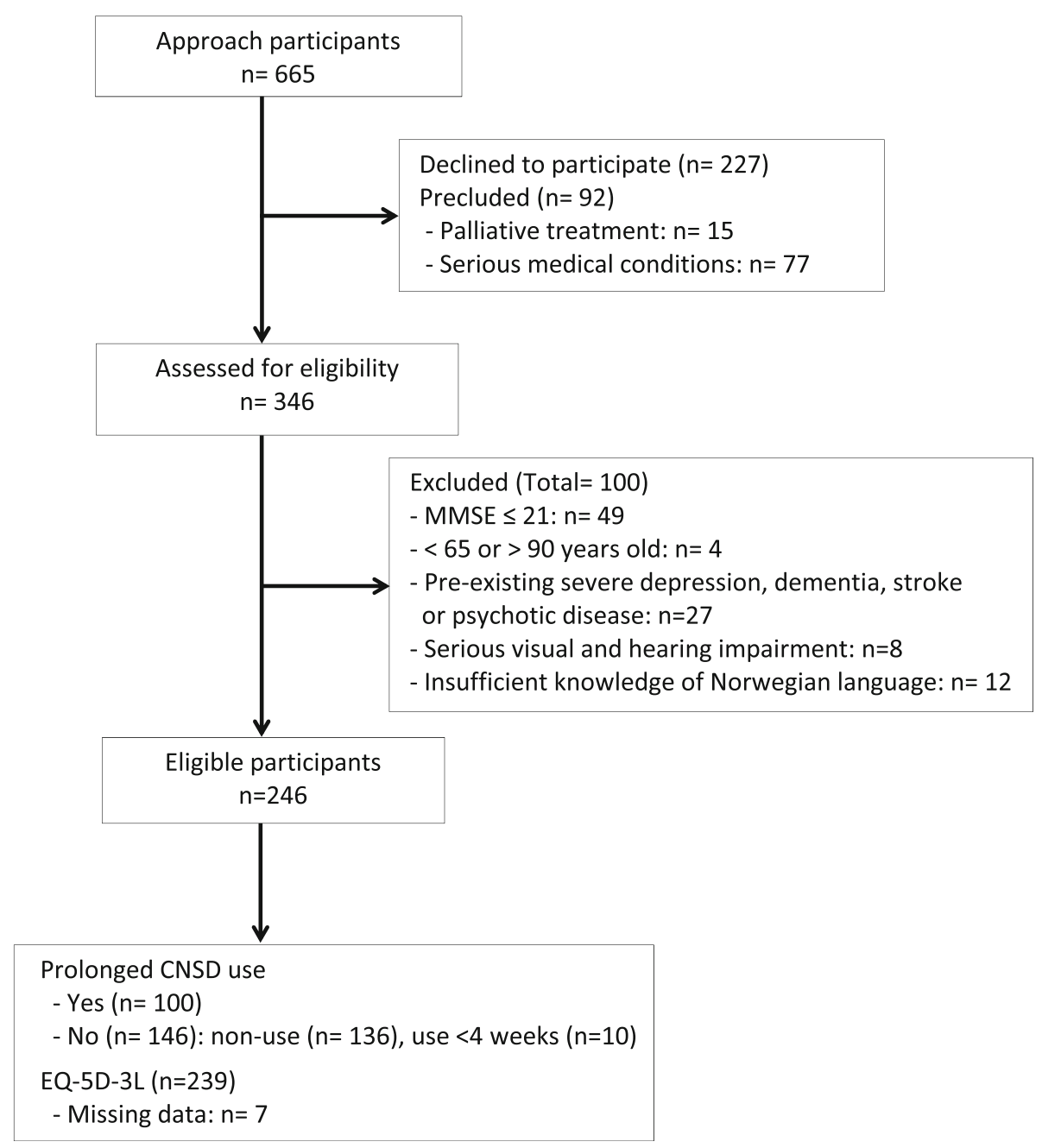

Fig. 1 Flow of participants through the study 
Table 1 Characteristics of participants, number (\%) unless stated otherwise

\begin{tabular}{|c|c|c|c|}
\hline & \multicolumn{3}{|c|}{ Prolonged CNSD use } \\
\hline & $\begin{array}{l}\text { No } \\
(n=146)\end{array}$ & $\begin{array}{l}\text { Yes } \\
(n=100)\end{array}$ & $p$-value \\
\hline Sex, female & $71(49)$ & $66(66)$ & 0.009 \\
\hline Age in years, mean (SD) & $75(6.4)$ & $78(6.5)$ & $<0.001$ \\
\hline \multicolumn{4}{|l|}{ Education } \\
\hline Secondary education & $64(46)$ & $31(33)$ & 0.001 \\
\hline Higher education & $58(42)$ & $33(35)$ & \\
\hline Living alone & $59(40)$ & $55(55)$ & 0.03 \\
\hline Polypharmacy, $\geq 5$ drugs/day & $91(62)$ & $92(92)$ & $<0.001$ \\
\hline Comorbidity burden (CIRS-G scores), mean (SD) & $4.6(2.2)$ & $7.7(2.7)$ & $<0.001$ \\
\hline \multicolumn{4}{|l|}{ Hospital anxiety and depression scale } \\
\hline Anxiety score (HADS-A), median (IQR) & $4(1$ to 6$)$ & $4(2$ to 8$)$ & 0.17 \\
\hline Depression score (HADS-D), median (IQR) & $3(1$ to 6$)$ & $4(2$ to 7$)$ & $<0.001$ \\
\hline Pain intensity (VAS in centimeters), median (IQR) & 0.7 (0.03 to 2.7$)$ & $2.9(0.5$ to 6.1$)$ & $<0.001$ \\
\hline
\end{tabular}

Abbreviations:CNSD Central nervous system depressant drugs, CIRS-G Cumulative Illness Rating Scale-Geriatrics, VAS Visual analogue scale, SD Standard deviation, $I Q R$ Interquartile range

Comparison of HRQoL between patients with and without prolonged CNSD use

Patients with prolonged use of CNSDs reported greater problems concerning mobility, self-care, usual activities, pain/discomfort and anxiety/depression (dimensions of the EQ-5D) than those without prolonged use. They also had lower EQ VAS scores, mean 50 (SD 17) than those without such use, mean 62 (SD 23), $p<0.001$ (Table 2). Patients with prolonged CNSD use reported lower EQ5D index scores (median 0.19, IQR: 0.002 to 0.69 ) than those without (median 0.73, IQR: 0.30 to 0.81 ), $p<$ 0.001 . In our post-hoc analyses, we did not find differences in EQ VAS and EQ-5D index scores between patients who used just 1 type and those concurrently used $\geq 2$ types of CNSDs. Also, EQ VAS and EQ-5D index scores of opioid, benzodiazepine and z-hypnotic users did not differ (data not shown).

\section{Association between prolonged use of CNSDs and HRQoL in multivariable analyses \\ Dimensions of HRQoL}

In multiple logistic regression analyses (Table 3), we found that the odds of having extreme versus moderate/ no pain or discomfort, and also the odds of having moderate/extreme versus no pain or discomfort for patients with prolonged CNSD use were about two times higher than that of those without such use $(\mathrm{OR}=2.06,95 \% \mathrm{CI}$ 1.05 to 4.04). Patients with prolonged CNSD use were four times more likely than those without prolonged use to be extremely versus moderately/not anxious or depressed, or moderately/extremely versus not anxious or depressed (OR $=3.77$, 95\% CI: 1.82 to 7.82 ). Also, using CNSDs for $\geq 4$ weeks was associated with increased odds of having problems performing usual activities ( $\mathrm{OR}=$ 3.37, 95\% CI: 1.40 to 8.13 ). In addition, we found that polypharmacy was associated with problems performing usual activities and mobility. The odds of being confined to bed versus no/some problems in walking about, and also the odds of being confined to bed/some problems in walking about versus no problems in walking about for patients with polypharmacy were 3.58 times higher than that of those without polypharmacy $(\mathrm{OR}=3.58$, 95\% CI: 1.77 to 7.22 ). The odds of being unable to perform usual activities versus some/no problems with performing usual activities, and also the odds of being unable/some problems versus no problems with performing usual activities for patients with polypharmacy were 2.73 times higher compared to those without polypharmacy (OR $=2.73,95 \% \mathrm{CI}: 1.28$ to 5.84$)$.

\section{Global score of HRQoL (EQ-5D index)}

In hierarchical multiple linear regression analyses, we found that older patients who had used CNSDs for $\geq 4$ weeks had lower EQ-5D index scores, regression coefficient -0.20 ( $95 \%$ CI: -0.32 to $-0.08, p=0.002$ ) than that of those without such use, adjusted for age, sex, education, living alone, polypharmacy and comorbidity burden (Table 4, Model 1). In Model 2, when adding adjustment for anxiety scores (HADS-A) and depression scores (HADS-D) to the Model 1 , the regression coefficient barely changed, -0.19 (95\% CI: -0.31 to $-0.06, p=0.004)$. However, in Model 3 (adding the variable pain intensity to the Model 2), the coefficient for prolonged CNSD use was -0.08 (95\% CI: -0.21 to $0.05, p=0.24)$, while pain intensity -0.06 (95\% CI: -0.08 to $-0.04, p<$ 0.001 ), and depression score -0.02 (95\% CI: -0.04 
Table 2 Health-related quality of life of patients with versus without prolonged CNSD use

\begin{tabular}{|c|c|c|c|}
\hline & \multicolumn{2}{|c|}{ Prolonged CNSD use } & \multirow[b]{2}{*}{$p$-value } \\
\hline & No $(n=146)$ & Yes $(n=100)$ & \\
\hline \multicolumn{4}{|l|}{ Dimensions of HRQoL, n (\%) } \\
\hline \multicolumn{4}{|l|}{ Mobility } \\
\hline No problems in walking about & $60(42)$ & $16(17)$ & \multirow[t]{3}{*}{$<0.001$} \\
\hline Some problems in walking about & $59(41)$ & $52(54)$ & \\
\hline Being confined to bed & $24(17)$ & $28(29)$ & \\
\hline \multicolumn{4}{|l|}{ Self-care } \\
\hline No problems with self-care & $109(76)$ & $50(52)$ & \multirow[t]{3}{*}{$<0.001$} \\
\hline Some problems with self-care & $28(20)$ & $40(42)$ & \\
\hline Being unable to wash or dress myself & $6(4)$ & $6(6)$ & \\
\hline \multicolumn{4}{|l|}{ Usual activities } \\
\hline No problems with performing my usual activities & $77(54)$ & $16(17)$ & \multirow[t]{3}{*}{$<0.001$} \\
\hline Some problems with performing my usual activities & $45(31)$ & $61(63)$ & \\
\hline Being unable to perform my usual activities & $21(15)$ & $19(20)$ & \\
\hline \multicolumn{4}{|l|}{ Pain/discomfort } \\
\hline No pain or discomfort & $48(34)$ & $19(20)$ & \multirow[t]{3}{*}{0.02} \\
\hline Moderate pain or discomfort & $76(53)$ & $53(55)$ & \\
\hline Extreme pain or discomfort & $19(13)$ & $24(25)$ & \\
\hline \multicolumn{4}{|l|}{ Anxiety/depression } \\
\hline Not being anxious or depressed & $96(67)$ & $40(42)$ & \multirow[t]{3}{*}{$<0.001$} \\
\hline Being moderately anxious or depressed & $44(31)$ & $47(49)$ & \\
\hline Being extremely anxious or depressed & $3(2)$ & $9(9)$ & \\
\hline EQ VAS, mean (SD) & $62(23)$ & $50(17)$ & $<0.001$ \\
\hline Global score of HRQoL (EQ-5D index), median (IQR) & 0.73 (0.30 to 0.81$)$ & 0.19 (0.002 to 0.69$)$ & $<0.001$ \\
\hline
\end{tabular}

Abbreviations: CNSDs Central nervous system depressant drugs; VAS Visual analogue scale, SD Standard deviation, IQR Interquartile range

to $-0.001, p=0.04$ ) were statistically significant. Polypharmacy was associated with reduced EQ-5D index in all models, with the regression coefficient ranging from -0.12 to -0.15 . Residual diagnostics was performed, and even though some minor deviation from model assumptions were observed, the bootstrap-based inference did not change the results.

\section{Discussion}

This study has shown that older patients who had used CNSDs $\geq 4$ weeks had poorer HRQoL than those with non-use or use $<4$ weeks, but also that the presence of pain as a confounder modified this finding. Patients using CNSDs reported lower EQ VAS and EQ-5D index scores and had higher odds of having impairment in several dimensions of the EQ-5D (usual activities, pain/

Table 3 Multiple logistic regression analyses of the association between prolonged use of CNSDs and the five dimensions of HRQoL

\begin{tabular}{|c|c|c|c|c|c|}
\hline \multirow[t]{2}{*}{ Independent variable } & \multicolumn{5}{|l|}{ EQ-5D dimensions } \\
\hline & $\begin{array}{l}\text { Mobility } \\
\text { OR }(95 \% \mathrm{Cl})\end{array}$ & $\begin{array}{l}\text { Self-care }{ }^{a} \\
\text { OR }(95 \% \mathrm{Cl})\end{array}$ & $\begin{array}{l}\text { Usual activities }^{\text {b }} \\
\text { OR }(95 \% \mathrm{Cl})\end{array}$ & $\begin{array}{l}\text { Pain/discomfort }{ }^{\mathrm{a}} \\
\text { OR }(95 \% \mathrm{Cl})\end{array}$ & $\begin{array}{l}\text { Anxiety/depression }{ }^{a} \\
\text { OR }(95 \% \mathrm{Cl})\end{array}$ \\
\hline Prolonged CNSD use, yes versus no & $1.22(0.61$ to 2.44$)$ & 1.49 (0.68 to 3.25$)$ & 3.37 (1.40 to 8.13$)$ & 2.06 (1.05 to 4.04$)$ & $3.77(1.82$ to 7.82$)$ \\
\hline Polypharmacy, $\geq 5$ versus $<5$ drugs/day & 3.58 (1.77 to 7.22$)$ & 1.67 (0.71 to 3.95$)$ & 2.73 (1.28 to 5.84$)$ & 1.65 (0.86 to 3.17$)$ & $0.55(0.27$ to 1.10$)$ \\
\hline Comorbidity burden (CIRS-G total score) & 1.08 (0.97 to 1.20$)$ & 1.05 (0.93 to 1.19$)$ & 1.02 (0.87 to 1.19$)$ & 1.08 (0.96 to 1.21$)$ & 0.96 (0.85 to 1.07$)$ \\
\hline Anxiety score (HADS-A) & 0.96 (0.87 to 1.06$)$ & 0.94 (0.84 to 1.05$)$ & $1.01(0.90$ to 1.15$)$ & 1.11 (1.01 to 1.22$)$ & N/A \\
\hline Depression score (HADS-D) & 1.15 (1.04 to 1.28$)$ & 1.18 (1.05 to 1.33$)$ & 1.16 (1.01 to 1.33$)$ & $1.00(0.90$ to 1.11$)$ & N/A \\
\hline Pain intensity (VAS) & 1.17 (1.06 to 1.29$)$ & 1.19 (1.06 to 1.33$)$ & $1.20(1.04$ to 1.37$)$ & N/A & 1.05 (0.95 to 1.17$)$ \\
\hline
\end{tabular}

Note: all models are adjusted for age, sex, education and living alone. ${ }^{a}$ : Ordered logistic regression, ${ }^{\mathrm{b}}$ : Binary logistic regression

Abbreviations: OR Odds ratio, CNSDs Central nervous system depressant drugs, HADS-D/A Hospital anxiety and depression sub-scales, VAS Visual analogue scale, $N$ / $A$ Not applicable, $C I$ Confidence interval, CIRS-G Cumulative illness rating scale for Geriatrics 
Table 4 Multiple linear regression analyses of the association between prolonged use of CNSDs and the global score of HRQoL (EQ5D index)

\begin{tabular}{|c|c|c|c|c|c|c|}
\hline \multirow[t]{2}{*}{ Independent variable } & \multicolumn{2}{|l|}{ Model 1} & \multicolumn{2}{|l|}{ Model 2} & \multicolumn{2}{|l|}{ Model 3} \\
\hline & $\begin{array}{l}\text { Regression coefficient } \\
(95 \% \mathrm{Cl})\end{array}$ & $\overline{p \text {-value }}$ & $\begin{array}{l}\text { Regression coefficient } \\
(95 \% \mathrm{Cl})\end{array}$ & $\overline{p \text {-value }}$ & $\begin{array}{l}\text { Regression coefficient } \\
(95 \% \mathrm{Cl})\end{array}$ & $p$-value \\
\hline Prolonged CNSD use & $-0.20(-0.32$ to -0.08$)$ & 0.002 & $-0.19(-0.31$ to -0.06$)$ & 0.004 & $-0.08(-0.21$ to 0.05$)$ & 0.24 \\
\hline Polypharmacy, $\geq 5$ versus $<5$ drugs/day & $-0.15(-0.27$ to -0.04$)$ & 0.01 & $-0.15(-0.26$ to -0.03$)$ & 0.01 & $-0.12(-0.23$ to -0.01$)$ & 0.04 \\
\hline Comorbidity burden (CIRS-G total score) & $-0.01(-0.04$ to 0.01$)$ & 0.21 & $-0.01(-0.03$ to 0.01$)$ & 0.27 & $-0.01(-0.03$ to 0.01$)$ & 0.22 \\
\hline Anxiety score (HADS-A) & & & $-0.02(-0.03$ to 0.003$)$ & 0.10 & $-0.01(-0.03$ to 0.01$)$ & 0.20 \\
\hline Depression score (HADS-D) & & & $-0.02(-0.04$ to 0.002$)$ & 0.08 & $-0.02(-0.04$ to -0.001$)$ & 0.04 \\
\hline Pain intensity (VAS), per $\mathrm{cm}$ & & & & & $-0.06(-0.08$ to -0.04$)$ & $<0.001$ \\
\hline Adjusted R-squared & 0.13 & & 0.19 & & 0.34 & \\
\hline
\end{tabular}

Note: all models are adjusted for age, sex, education and living alone

Abbreviations: CNSD Central nervous system depressant drugs, HADS-D/A Hospital anxiety and depression sub-scales, VAS Visual analogue scale, CI Confidence interval, CIRS-G Cumulative illness rating scale for Geriatric

discomfort and anxiety/depression). There was no association between CNSD use and higher HRQoL. We found an inverse relationship between prolonged CNSD use and older patients' overall HRQoL as assessed with EQ-5D index, in a model adjusted for sociodemographic variables, polypharmacy, comorbidity burden, anxiety and depressive symptoms. In an additional regression model which also included pain, this relationship was no longer significant. When pain was also included in the model, only pain, depression, and presence of polypharmacy were significantly associated with lower HRQoL.

A strength of this study is that it focused specifically on HRQoL of older patients with versus without prolonged use of CNSDs. Moreover, we had the opportunity to adjust for clinically important and often-neglected variables such as comorbidity burden and polypharmacy. Our study has some limitations. It was not designed for and did not have sufficient power to study associations with subgroups of CNSD separately. However, our focus has been the combined effect of the whole CNSD medication group as these drugs are commonly prescribed together for older patients. Thus, we suggest that our findings reflect a pragmatic real life situation, which may, in fact, be missed in studies focusing on separate medications. The use of a cross-sectional design precludes us from inferring direction of causation. Possibly, prolonged use of CNSDs leads to health problems such as difficulty performing usual activities, pain/discomfort, and anxiety/depression. However, the reverse is also possible as rebound anxiety and opioid-induce hyperalgesia may occur [26-28]. Future longitudinal or intervention studies should clarify this. The study may be still subject to confounding by indication as we have not assayed any parameters related to sleep and have no possibility to reconstruct the design. However, the observed associations were examined with multivariable regression models, adjusting for variables which are clinical indications for
CNSD therapy such as pain, anxiety and depression. The effect of confounding by indication was therefore partly addressed. We calculated EQ-5D index scores based on the value set for England, as a tariff was not available for Norway. Using a consecutive hospital-based sample limits the generalizability of the study findings. However, our sample constitutes patients admitted to clinical wards regardless of their socioeconomic background and for a variety of health problems, and as such should be representative for hospital populations of older patients, admitted to geriatric, general internal medicine and neurology departments.

Our study showed that patients with prolonged CNSD use reported poorer HRQoL than those without prolonged use (Table 2). As the most severely afflicted patients were excluded, mainly for ethical reasons, our results may be somewhat biased towards milder cases. This may suggest that, could the most severe cases have been included, the effect size may have been even larger. A systematic review, though not focused on older patients, pointed out that there is only weak evidence that long-term opioid therapy may improve HRQoL [29].

The finding that depression scores were higher among prolonged CNSD users than those without such use ties in well with previous studies. Both randomized and nonrandomized studies have shown that the use of benzodiazepines and z-hypnotics may increase the risk of subsequent depression [30, 31]. Depression may worsen pain intensity and erodes opioid analgesic potency, challenging the treatment of chronic pain. Depressed patients are also more likely to initiate and continue using opioids than those without depression [32, 33]. In the present study, depression was negatively associated with patients' overall HRQoL, as assessed with the EQ-5D index, in line with other studies [34, 35].

Our study showed that polypharmacy was associated with impairment in two dimensions of HRQoL. Also, 
polypharmacy was inversely associated with patients' overall HRQoL, as assessed with the EQ-5D index score in all the three multiple linear regression models. These findings are consistent with some previous studies [36, 37].

This study also indicated that patients with prolonged CNSD use had more intense pain then those without such use, and that pain intensity was associated with lower HRQoL. These results support previous studies $[38,39]$. In two of the hierarchical multiple linear regression models, prolonged CNSD use was associated with the EQ-5D index. However, when adding the variable pain intensity (VAS) to the model, the observed association between prolonged CNSD and the EQ-5D index was no longer statistically significant, accompanied by a $15 \%$ increase in the adjusted R-squared value. Hence, pain intensity may better explain the variance in EQ-5D index, beyond those variables in the Model 2. It is possible that the observed association between prolonged CNSD use and EQ-5D index (Model 2) was confounded by pain intensity, as patients with prolonged CNSD use had more pain than the reference group, and that pain intensity had a negative relationship with the EQ-5D index. Alternatively, pain intensity may operate as an intermediate step between prolonged CNSD use and HRQoL.

\section{Clinical implication}

It was unknown whether persistent use of CNSD medications was beneficial for older patients' HRQoL. This study indicates that older patients with prolonged CNSD use have poorer HRQoL and higher odds of having impairment in multiple dimensions of HRQoL than those without such use. After adjusting for current pain in multivariable analyses, an approach which has been discussed due to the complex nature of pain as a symptom [40], prolonged use of CNSDs is not independently associated with higher HRQoL.

\section{Conclusions}

Older patients with prolonged use of CNSDs do not have better HRQoL than those without such use. The presence of pain as well as anxiety and depression seem to be important predictors and our study emphasizes the importance of considering these factors carefully in assessing the indications for long-term CNSD treatment among older patients. Further prospective longitudinal studies are necessary for assessing direction of causality.

\section{Abbreviations}

CNSD: Central nervous system depressant drugs; HRQoL: Health-related quality of life; HADS-D/A: Hospital anxiety and depression sub-scales; VAS: Visual analogue scale; CIRS-G: Cumulative illness rating scale for Geriatrics; OR: Odd ratio; Cl: Confidence interval; SD: Standard deviation; IQR: Interquartile range

\section{Acknowledgements}

We thank all participants and staff for spending their time and effort on this study. We also appreciate the statistical support of Professor Jurate Š Benth.

\section{Authors' contributions}

SC, TGS, MG, KS, ESK, and CL contributed to the study conception. SC and CL designed and wrote the protocol. SC, TGS and CL recruited participants and collected data. SC, KS and CL analyzed data. SC drafted the original manuscript. SC, TGS, MG, KS, ESK, and CL took part in project planning. SC, TGS, MG, KS, ESK, and CL critically reviewed and approved the final version of this manuscript.

\section{Funding}

This study was funded by a grant from the Norwegian Research Council (Project number 256431), the University of Oslo and the Health Services Research Unit of the Akershus University Hospital. The funders had no role in study design, data collection and analysis, decision to publish or preparation of the manuscript.

\section{Availability of data and materials}

The datasets generated and/or analyzed during the current study are available from the corresponding author on reasonable request.

\section{Ethics approval and consent to participate}

Ethical approval was obtained from the Regional Committee for Medical Research Ethics - South East Norway (Reference number: 2016/2289/REK Sør$\varnothing$ st) and the Data Protection Office at Akershus University Hospital (Reference number: 17-054). All participants provided written informed consents.

\section{Consent for publication}

Not applicable.

\section{Competing interests}

$\mathrm{CL}$ reports having received research grants from the South-East Regional Health authority, during the conduct of the study as well as grants and personal fees from Abbvie pharma AS and Roche Norway AS, outside this submitted work. The agencies had no role in study design, data collection and analysis, decision to publish or preparation of the manuscript. Other authors declared no conflicts of interest.

\section{Author details}

'Health Services Research Unit $(\mathrm{H} \varnothing \mathrm{KH})$, Akershus University Hospital, PO Box 1000, 1478 Lørenskog, Norway. ${ }^{2}$ Institute of Clinical Medicine, Campus Ahus, Faculty of Medicine, University of Oslo, Lørenskog, Norway. ${ }^{3}$ National

Addiction Centre, Institute of Psychiatry, Psychology and Neuroscience, King's College London, London, UK. ${ }^{4}$ Department of Pulmonary Medicine, Akershus University Hospital, Lørenskog, Norway. ${ }^{5}$ Department of General Practice, Institute of Health and Society, University of Oslo, Oslo, Norway. ${ }^{6}$ Department of Neurology, Akershus University Hospital, Lørenskog, Norway.

Received: 8 October 2019 Accepted: 19 October 2020

Published online: 23 October 2020

\section{References}

1. Karimi M, Brazier J. Health, health-related quality of life, and quality of life: what is the difference? PharmacoEconomics. 2016;34(7):645-9.

2. Fedarko NS. The biology of aging and frailty. Clin Geriatr Med. 2011;27(1): 27-37.

3. Stites SD, Harkins K, Rubright JD, Karlawish J. Relationships between cognitive complaints and quality of life in older adults with mild cognitive impairment, mild Alzheimer disease dementia, and normal cognition. Alzheimer Dis Assoc Disord. 2018;32(4):276-83.

4. Atkins J, Naismith SL, Luscombe GM, Hickie IB. Psychological distress and quality of life in older persons: relative contributions of fixed and modifiable risk factors. BMC psychiatry. 2013;13(1):249.

5. Olsson IN, Runnamo R, Engfeldt P. Medication quality and quality of life in the elderly, a cohort study. Health Qual Life Outcomes. 2011;9(1):95.

6. Dunietz GL, Swanson LM, Jansen EC, Chervin RD, O'Brien LM, Lisabeth LD, et al. Key insomnia symptoms and incident pain in older adults: direct and mediated pathways through depression and anxiety. Sleep. 2018;41(9): zsy 125 . 
7. World Health Organization. Lexicon of alcohol and drug terms. Geneva: World Health Organization; 1994.

8. Papaleontiou M, Henderson J, Charles R, Turner BJ, Moore AA, Olkhovskaya $Y$, Amanfo $L$, et al. Outcomes associated with opioid use in the treatment of chronic noncancer pain in older adults: a systematic review and metaanalysis. J Am Geriatr Soc. 2010;58(7):1353-69.

9. McMillan JM, Aitken E, Holroyd-Leduc JM. Management of insomnia and long-term use of sedative-hypnotic drugs in older patients. CMAJ. 2013; 185(17):1499-505.

10. Cheng S, Siddiqui TG, Gossop M, Kristoffersen ES, Lundqvist C. Sociodemographic, clinical and pharmacological profiles of medication misuse and dependence in hospitalised older patients in Norway: a prospective cross-sectional study. BMJ Open. 2019:9(9):e031483.

11. Galicia-Castillo M. Opioids for persistent pain in older adults. Cleve Clin J Med. 2016:83(6):443-51.

12. Brandt J, Leong C. Benzodiazepines and Z-drugs: an updated review of major adverse outcomes reported on in epidemiologic research. Drugs in R\&D. 2017;17(4):493-507.

13. Carlsten A, Waern M. Are sedatives and hypnotics associated with increased suicide risk of suicide in the elderly? BMC Geriatr. 2009;9(1):20.

14. Mannucci PM, Nobili A, Investigators R. Multimorbidity and polypharmacy in the elderly: lessons from REPOSI. Intern Emerg Med. 2014;9(7):723-34.

15. Karlawish J. Measuring decision-making capacity in cognitively impaired individuals. Neurosignals. 2008;16(1):91-8.

16. Brooks R, Group E. EuroQol: the current state of play. Health policy. 1996; 37(1):53-72.

17. Hawker GA, Mian S, Kendzerska T, French M. Measures of adult pain: visual analog scale for pain (vas pain), numeric rating scale for pain (nrs pain), mcgill pain questionnaire (mpq), short-form mcgill pain questionnaire (sf$\mathrm{mpq}$ ), chronic pain grade scale (cpgs), short form-36 bodily pain scale (sf-36 bps), and measure of intermittent and constant osteoarthritis pain (icoap). Arthritis Care Res. 2011;63(S11):S240-S52.

18. Zigmond AS, Snaith RP. The hospital anxiety and depression scale. Acta Psychiatr Scand. 1983;67(6):361-70.

19. Miller MD, Paradis CF, Houck PR, Mazumdar S, Stack JA, Rifai AH, et al. Rating chronic medical illness burden in geropsychiatric practice and research: application of the cumulative illness rating scale. Psychiatry Res. 1992:41(3):237-48

20. Gnjidic D, Hilmer SN, Blyth FM, Naganathan V, Waite L, Seibel MJ, et al. Polypharmacy cutoff and outcomes: five or more medicines were used to identify community-dwelling older men at risk of different adverse outcomes. J Clin Epidemiol. 2012;65(9):989-95.

21. Helvik A-S, Engedal K, Skancke RH, Selbæk G. A psychometric evaluation of the hospital anxiety and depression scale for the medically hospitalized elderly. Nordic J Psychiatry. 2011;65(5):338-44.

22. Djukanovic I, Carlsson J, Årestedt K. Is the hospital anxiety and depression scale (HADS) a valid measure in a general population 65-80 years old? A psychometric evaluation study. Health Qual Life Outcomes. 2017;15(1):193.

23. Salvi F, Miller MD, Grilli A, Giorgi R, Towers AL, Morichi $V$, et al. A manual of guidelines to score the modified cumulative illness rating scale and its validation in acute hospitalized elderly patients. J Am Geriatr Soc. 2008; 56(10):1926-31.

24. Erkan A, Yildiz Z. Parallel lines assumption in ordinal logistic regression and analysis approaches. Int Interdisciplinary J Sci Res. 2014;1:10-11.

25. Hattori Y, Katayama M, Kida D, Kaneko A. Hospital anxiety and depression scale score is an independent factor associated with the EuroQoL 5dimensional descriptive system in patients with rheumatoid arthritis. J Clin Rheumatol. 2018;24(6):308-12.

26. Lader M. Benzodiazepines revisited —will we ever learn? Addiction. 2011; 106(12):2086-109.

27. Tanguay Bernard M-M, Luc M, Carrier J-D, Fournier L, Duhoux A, Côté E, et al. Patterns of benzodiazepines use in primary care adults with anxiety disorders. Heliyon. 2018;4(7):e00688

28. Samuelsen P-J, Nielsen CS, Wilsgaard T, Stubhaug A, Svendsen K, Eggen AE. Pain sensitivity and analgesic use among 10,486 adults: the Troms $\varnothing$ study. BMC Pharmacol Toxicol. 2017;18(1):45

29. Noble M, Treadwell JR, Tregear SJ, Coates VH, Wiffen PJ, Akafomo C, et al. Long-term opioid management for chronic noncancer pain. Cochrane Database Syst Rev. 2010;2010(1):CD006605.

30. Kripke DF. Greater incidence of depression with hypnotic use than with placebo. BMC Psychiatry. 2007;7(1):42.
31. Nordfjærn T. A population-based cohort study of anxiety, depression, sleep and alcohol outcomes among benzodiazepine and z-hypnotic users. Addict Behav. 2012;37(10):1151-7.

32. Sullivan MD. Depression effects on long-term prescription opioid use, abuse, and addiction. Clin J Pain. 2018;34(9):878-84.

33. Halbert B, Davis R, Wee CC. Disproportionate longer-term opioid use among US adults with mood disorders. Pain. 2016;157(11):2452.

34. Sobocki P, Ekman M, Ågren H, Krakau I, Runeson B, Mårtensson B, et al. Health-related quality of life measured with EQ-5D in patients treated for depression in primary care. Value Health. 2007;10(2):153-60.

35. Ko Y, Coons SJ. Self-reported chronic conditions and EQ-5D index scores in the US adult population. Curr Med Res Opin. 2006;22(10):2065-71.

36. Zhang S, Meng L, Qiu F, Yang JD, Sun S. Medication-related risk factors associated with health-related quality of life among community-dwelling elderly in China. Patient Prefer Adherence. 2018;12:529-37.

37. Montiel-Luque A, Núñez-Montenegro AJ, Martin-Aurioles E, Canca-Sánchez JC, Toro-Toro MC, González-Correa JA, et al. Medication-related factors associated with health-related quality of life in patients older than 65 years with polypharmacy. PLoS One. 2017;12(2):e0171320.

38. Dueñas M, Ojeda B, Salazar A, Mico JA, Failde I. A review of chronic pain impact on patients, their social environment and the health care system. J Pain Res. 2016:9:457.

39. Hadi MA, McHugh GA, Closs SJ. Impact of chronic pain on patients' quality of life: a comparative mixed-methods study. J Patient Exp. 2019;6(2):133-41.

40. Pérez C, Margarit C, Sánchez-Magro I, de Antonio A, Villoria J. Chronic pain features relate to quality of life more than physiopathology: a crosssectional evaluation in pain clinics. Pain Pract. 2017;17(7):866-78.

\section{Publisher's Note}

Springer Nature remains neutral with regard to jurisdictional claims in published maps and institutional affiliations.

\section{Ready to submit your research? Choose BMC and benefit from:}

- fast, convenient online submission

- thorough peer review by experienced researchers in your field

- rapid publication on acceptance

- support for research data, including large and complex data types

- gold Open Access which fosters wider collaboration and increased citations

- maximum visibility for your research: over $100 \mathrm{M}$ website views per year

At $\mathrm{BMC}$, research is always in progress.

Learn more biomedcentral.com/submissions 